\title{
Automatic Plants Watering System for Small Garden
}

\author{
https://doi.org/10.3991/ijim.v15i02.12803 \\ Maria Beata Inka Astutiningtyas, \\ Monika Margi Nugraheni, Suyoto $(\varpi)$ \\ Universitas Atma Jaya Yogyakarta, Yogyakarta, Indonesia \\ suyotodstaff.uajy.ac.id
}

\begin{abstract}
Background: Automation is starting to dominate the world today. We are entering a new era of computing technology, the Internet of Things (IoT), which is experiencing rapid development. IoT is a worldwide neural network in the cloud that connects a mixture of things, aiming to maximize internet connectivity benefits in transferring and processing data. Using IoT, one can monitor and control a device remotely with a computer or smartphone. IoT can apply in various fields, one of which is the smart garden. Objective: This research aims to design an automatic plant's watering system used in small gardens in houses. Smart Garden is an electronic control and garden monitoring system for the process of watering plants so that it can help people care for plants. Method: This paper presents a design of the Internet of Things for small gardens inside houses using Wireless networks and sensors. In automatic watering plants, information about soil moisture is needed for plants. Sensors are devices used for smart agriculture. Arduino Uno will control all system operations as monitoring the plant watering system. Result: The result of this paper is a Plants Watering System Design for Small Garden at Homes.
\end{abstract}

Keywords-Internet of Things (IoT), Smart Garden, IoT Application

\section{Introduction}

One of the things that can help IoT with daily activities is the agriculture section. Currently, the flawless integration with wireless sensors and IoT in smart agriculture can raise agriculture to a previously unthinkable [1]. The sales of agricultural products have always been challenging, so real-time monitoring in the processing, production, and circulation [2]. Supporting farmers with decision tools and automation technology is a purpose of application in agriculture. Integrate products, knowledge, and services for better quality, productivity, and profit expected to increase from 30 million in 2015 to 75 million in 2020 [3]. Smart Garden System is a breakthrough that is currently popular. At home, there are presently gardens in front and back yards. With uncertain climate change, a beautiful garden is needed and can provide coolness to the house. However, daily activities leave many people without enough time to water their plants. Plants that are not treated will wither and do not provide benefits.

Smart solutions are needed for better crop maintenance for more efficient water resources, even in adverse weather conditions. Besides, different plant species require 
different amounts of water, intelligent systems necessary for efficient water utilization and dynamic plant growth [4]. Because it becomes crucial to combine developing technology with plantations and carry out smart farms [5], the Smart Garden System appears. Features allow us to use various IoT applications such as integrating sensors/actuators, digital transmissions, low power consumption, scalability, and WSN security [6].

This system is a process in which automation water the garden through a humidity sensor in the ground or air. This system will facilitate with the help of the internet. The humidity sensor is connected to the watering plant and smartphone so we can monitor soil moisture. If the air or soil does not have enough water or humidity, the system will turn on the watering machine. Soil moisture, rainfall, evaporation are essential parameters for designing Smart Garden Systems [7], [8]. Some of the Smart Garden System's main features are real-time feedback from garden sensors, park monitoring, application-controlled water systems, and automatic watering systems. Mobile devices have robust computing, sensing, and connectivity resources. Tools such as smartphones and tablets can run applications for various purposes [9]. In this particular case, we would like to apply the Smart Garden System on mobile devices.

\section{$2 \quad$ Literature Review}

IoT technology plays an essential role in various applications in the agricultural sector. IoT uses the Cloud-Internet communication framework to store data in the cloud and process data outside the device [10]. IoT's real challenge is to allow users to control objects remotely more freely and flexibly [11]. It required communication and various assistance, such as local or remote data acquisition, intelligent information analysis, and cloud-based decision making for the farming industry. User interfaces and automation also can help to smooth the operations process. In the industrial chain, the agricultural sector is one of the most inefficient areas, but IoT can revolutionize it. [1]. The quality and safety of farm products are related to public health and can also affect social stability, economic development, and national security, which are global problems [2]. In this agriculture topic, a smart garden system for houses will significantly benefit a household. Using cloud computing and IoT, designing an irrigation system for monitoring soil moisture will help more efficient.

In agriculture and forestry, Cloud Computing and the Internet of Things (IoT) are already implemented. The advantages of Cloud Computing are virtualization, expansion, practical, and economical. The Internet of Things (IoT) plays as an essential supporter to realize intensive agriculture, high efficiency, high quality, high yield, ecological and safe with techniques such as photoacoustic electromagnetic sensors, technology " $3 \mathrm{~S}$ ", and laser scanner [12]. Cloud Computing and IoT are used to build agriculture automation by developing convenient measurement technologies and soil temperature, air humidity, and moisture sensors. By controlling the irrigation system for plants from a smartphone [13], [14]. It also developed with a Geographic Information System map of the land under control [15]. The data obtained using wireless 
communication, radio frequency identification, IoT information sensing techniques, automatic control handled with agricultural information cloud [16].

Critical applications using IoT include monitoring the quality of drinking water. Sensors measure water parameters installed to ensure high supply quality and avoid accidental contamination of drinking water connected to waste disposal. This same network expanded to monitor irrigation systems in plants [17]. A precise irrigation control system was developed using wireless sensors and scheduled to work according to remote sensor data using specific applications [18]. Gutiérrez et al. [9] designed an irrigation system using a camera embedded in a smartphone, enclosed in a waterproof and lightroom. The camera is to take pictures and check groundwater levels. According to the wet or dry soil sector, light and dark pixels are distinguished by grayscale analysis. Router nodes are used to pass on the valuable content that drives the sprinkler to provide water for plants automatically. Irrigation applications developed using smartphones and connectivity, including microprocessors, wifi, radio modem, and external memory.

\section{The Proposed Method}

In automatic watering plants, information about soil moisture is needed for plants. Sensors are devices used for smart agriculture. Real-time environmental parameters such as ambient temperature, soil moisture level, and tank water level significantly affect the continuation of the plant life cycle [19]. The soil moisture sensor is a sensor that can measure water content and soil moisture. Joaquin et al. [20] use solar power in irrigation systems that are significantly important for agricultural products and organic crops in geographically isolated places. This solar power will help where investments in the electricity supply will be expensive. Irrigation systems can also be adapted to various specific crop needs and only require minimum maintenance. Rao et al. [21] research research aims to monitor agricultural systems' data and control with high precision IoT technology. The IoT system used is Arduino and cloud to track real-time data from the crop field. This system focuses on humidity variations that connect with temperature change data by sensors and can control the watering system. To provide cloud-based computing to the system, the level of precision has increased according to farmers' use of the system. 


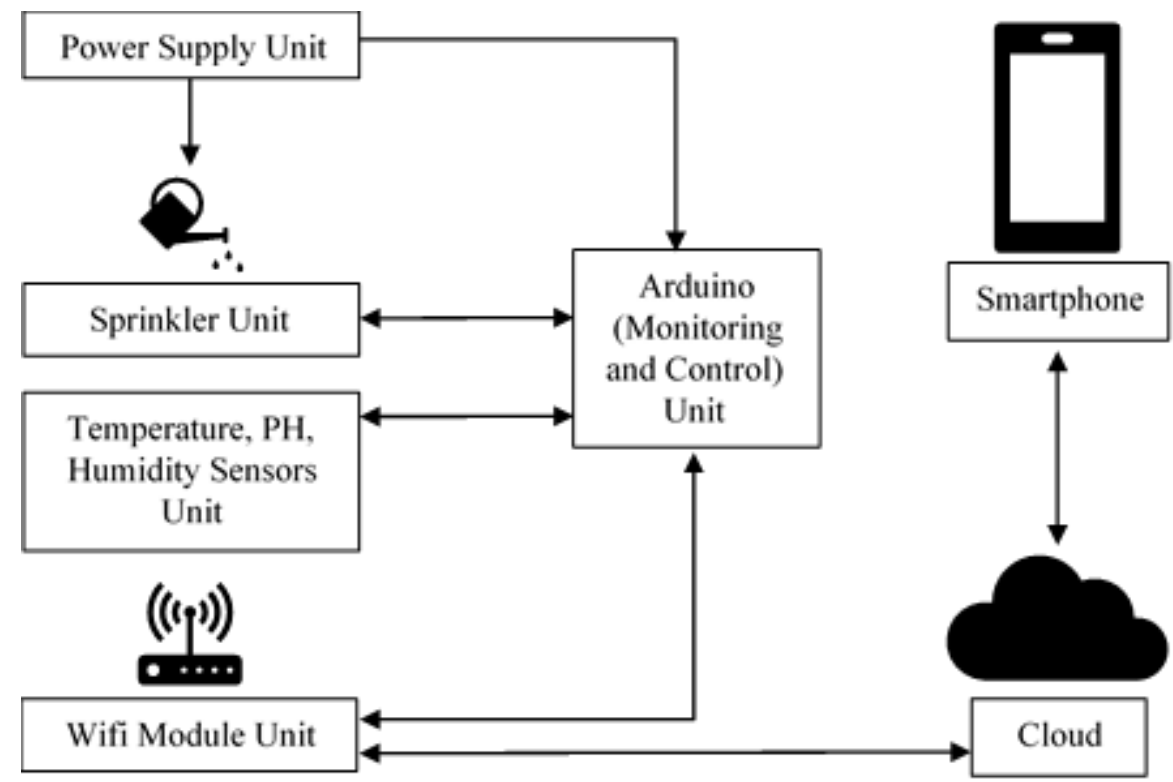

Fig. 1. Monitoring and control system architecture

As illustrated in Figure 1, all system operations are controlled by Arduino as monitoring and controlling. Arduino is an open-source prototyping platform. Arduino accepted input and converted it to consistent output [22]. The units connected to Arduino are the power supply unit, sprinkler unit, temperature, $\mathrm{PH}$, humidity sensors unit, wifi unit, and smartphone. Arduino will receive power from the power supply and collect temperature, PH, and Humidity data from the sensor's unit. Furthermore, the data is programmed displayed on a smartphone due to monitoring the garden's soil moisture using wifi.

This process is compiled by the Arduino Uno Board and becomes the primary control. The volume of water in the soil is measured by a soil moisture sensor consisting of 2 probes. These probes allow an electric current to pass through the land and measure soil moisture levels based on its resistance. When there is more water, the soil conducts more electricity and causes less resistance, so its humidity becomes high. Conversely, when there is less water, the ground conducts little electricity to lower soil moisture.

Figure 2 shows the flowchart of the system design. The power supply will be turned on and will initialize the connection with the Arduino Board. After initialization, the relationship with the wifi module established - authentication required for connections with sensors. The system will check the humidity level on the soil periodically and repeat the steps shown in Figure 2. 


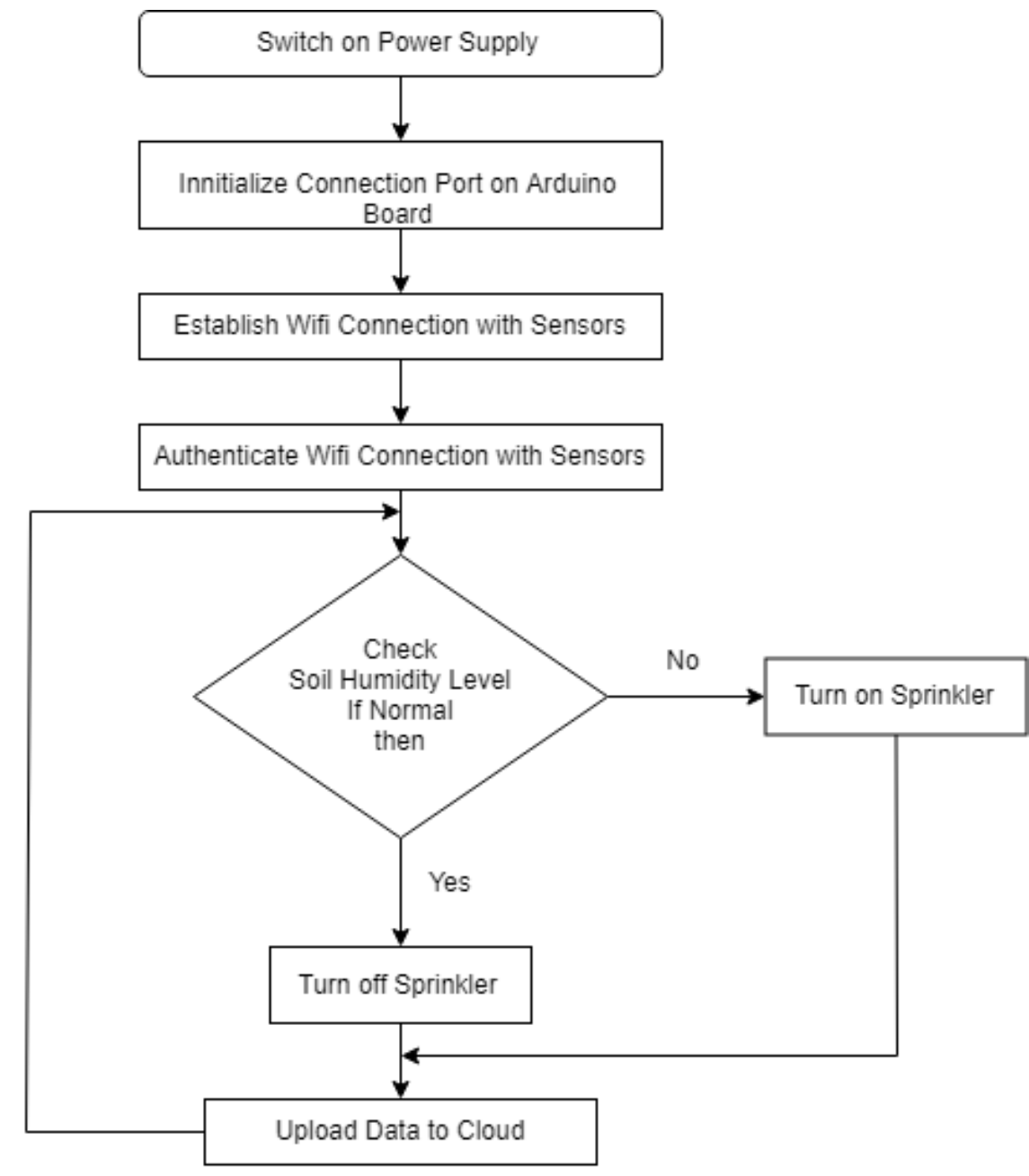

Fig. 2. Flowchart

The user interfaces are displayed on a smartphone, such as a Figure 3 display the temperature, humidity, soil $\mathrm{pH}$, and light information. Also, there are statistical charts for temperature every day. The home page also shows a button to activate the water sprinkler. Users can set when the water sprinkler is activated automatically with specific humidity. Users can also adjust the watering time. 

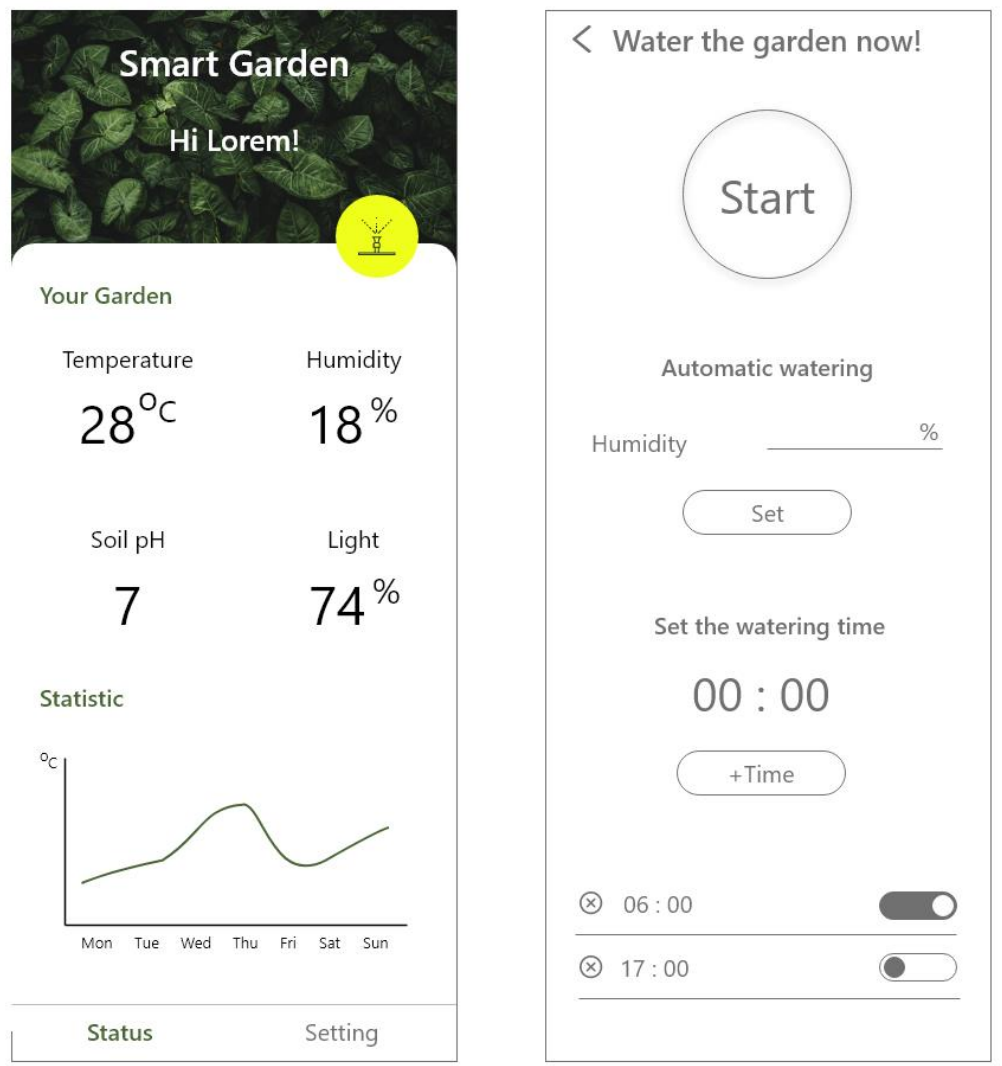

Fig. 3. Design User Interface

The proposed design application's contribution is to add smartphones as an interface application to control and monitor the plants watering systems. The proposed design aims to water the plants in homes on the garden on a small scale at a low cost. The component is connected via a smartphone as the interface, as shown in Figure 3. The sensor is buried in the ground and will send information about the moisture level of the soil. After the soil reaches the desired moisture level, it will turn off. The sprinkler turned on when the land's moisture level is below average - the monitored and controlled information transmitted into the smartphone through the wifi module.

\section{Conclusion}

Based on the explanation that elaborated, this paper's results are designing automatic plant watering systems for small gardens. There have been many studies on the agricultural industry. On this opportunity, the authors proposed a model of a watering system on a small scale. The design of this system utilizes Arduino Uno as a control 
board and monitor. With advances in technology and IoT, this design can help care for plants and assist in climate change.

\section{$5 \quad$ References}

[1] M. Ayaz, M. Ammaduddin, Z. Sharif, A. Mansour, and el-H. M. Aggoune, "Internet-ofThings (IoT) based Smart Agriculture: Towards Making the Fields Talk," IEEE Access, vol. 7, pp. 129551-129583, 2019. https://doi.org/10.1109/access.2019.2932609

[2] H. Ping, J. Wang, Z. Ma, and Y. Du, "Mini-review of application of iot technology in monitoring agricultural products quality and safety," Int. J. Agric. Biol. Eng., vol. 11, no. 5, pp. 35-45, 2018.

[3] O. Elijah, T. A. Rahman, I. Orikumhi, C. Y. Leow, and M. N. Hindia, "An Overview of Internet of Things (IoT) and Data Analytics in Agriculture: Benefits and Challenges," IEEE Internet Things J., vol. 5, no. 5, pp. 3758-3773, 2018. https://doi.org/10.1109/jiot.2018.28 $\underline{44296}$

[4] M. S. Munir, I. S. Bajwa, and S. M. Cheema, "An intelligent and secure smart watering system using fuzzy logic and blockchain," Comput. Electr. Eng., vol. 77, pp. 109-119, 2019. https://doi.org/10.1016/j.compeleceng.2019.05.006

[5] N. K. Nawandar and V. R. Satpute, "IoT based low cost and intelligent module for smart irrigation system," Comput. Electron. Agric., vol. 162, no. May, pp. 979-990, 2019. https ://doi.org/10.1016/j.compag.2019.05.027

[6] N. Ahmed, D. De, and I. Hussain, "Internet of Things (IoT) for Smart Precision Agriculture and Farming in Rural Areas," IEEE Internet Things J., vol. 5, no. 6, pp. 4890-4899, 2018. https://doi.org/10.1109/jiot.2018.2879579

[7] J. Muangprathub, N. Boonnam, S. Kajornkasirat, N. Lekbangpong, A. Wanichsombat, and P. Nillaor, "IoT and agriculture data analysis for smart farm," Comput. Electron. Agric., vol. 156, no. November 2018, pp. 467-474, 2019. https://doi.org/10.1016/j.compag.2018. $\underline{12.011}$

[8] A. Goap, D. Sharma, A. K. Shukla, and C. Rama Krishna, "An IoT based smart irrigation management system using Machine learning and open source technologies," Comput. Electron. Agric., vol. 155, no. September, pp. 41-49, 2018. https://doi.org/10.1016/i.comp ag.2018.09.040

[9] J. Gutiérrez, J. F. Villa-Medina, A. López-Guzmán, and M. Á. P.- Gándara, "Smartphone Irrigation Sensor,” IEEE Sens. J., vol. 15, no. 9, pp. 5122-5127, 2015. https://doi.org/10. $1109 /$ jsen.2015.2435516

[10] T. Alam and M. Benaida, "CICS: Cloud-internet communication security framework for the internet of smart devices," Int. J. Interact. Mob. Technol., vol. 12, no. 6, pp. 74-84, 2018. https://doi.org/10.3991/ijim.v12i6.6776

[11] R. Miramontes Meza, L. V. Escamilla del Río, and R. T. Aquino Santos, "Mobile Remote Control for Home Automation,” Int. J. Interact. Mob. Technol., vol. 7, no. 4, p. 21, 2013. https://doi.org/10.3991/ijim.v7i4.3178

[12] Y. Bo and H. Wang, "The application of cloud computing and the internet of things in agriculture and forestry,” Proc. - 2011 Int. Jt. Conf. Serv. Sci. IJCSS 2011, pp. 168-172, 2011.

[13] N. Kaewmard and S. Saiyod, "Sensor data collection and irrigation control on vegetable crop using smart phone and wireless sensor networks for smart farm," ICWiSe 2014 2014 IEEE Conf. Wirel. Sensors, pp. 106-112, 2014. https://doi.org/10.1109/icwise. $\underline{2014.7042670}$ 
[14] T. Ojha, S. Misra, and N. S. Raghuwanshi, "Wireless sensor networks for agriculture: The state-of-the-art in practice and future challenges," Comput. Electron. Agric., vol. 118, pp. 66-84, 2015. https://doi.org/10.1016/j.compag.2015.08.011

[15] M. A. Fourati, W. Chebbi, and A. Kamoun, "Development of a web-based weather station for irrigation scheduling," Colloq. Inf. Sci. Technol. Cist, vol. 2015-Janua, no. January, pp. 37-42, 2015. https://doi.org/10.1109/cist.2014.7016591

[16] F. TongKe, "Smart Agriculture Based on Cloud Computing and IOT," J. Converg. Inf. Technol., vol. 8, no. 2, pp. 210-216, 2013.

[17] J. Gubbi, R. Buyya, S. Marusic, and M. Palaniswami, "Internet of Things (IoT): A vision, architectural elements, and future directions," Futur. Gener. Comput. Syst., vol. 29, no. 7, pp. 1645-1660, 2013. https://doi.org/10.1016/j.future.2013.01.010

[18] D. D. Chaudhary, S. P. Nayse, and L. M. Waghmare, "Application of Wireless Sensor Networks for Greenhouse Parameter Control in Precision Agriculture," Int. J. Wirel. Mob. Networks, vol. 3, no. 1, pp. 140-149, 2011. https://doi.org/10.5121/ijwmn.2011.3113

[19] S. B. Saraf and D. H. Gawali, "IoT based smart irrigation monitoring and controlling system," RTEICT 2017 - 2nd IEEE Int. Conf. Recent Trends Electron. Inf. Commun. Technol. Proc., vol. 2018-Janua, pp. 815-819, 2018. https://doi.org/10.1109/rteict.2017.82567 $\underline{11}$

[20] J. Gutiérrez, J. F. Villa-Medina, A. Nieto-Garibay, and M. Á. Porta-Gándara, "An automated irrigation system using a wireless sensor network and GPRS module," IEEE Trans. Instrum. Meas., vol. 63, no. 1, pp. 166-176, 2014. https://doi.org/10.1109/tim.2013.22764 $\underline{87}$

[21] R. Nageswara Rao and B. Sridhar, "IoT based smart crop-field monitoring and automation irrigation system," Proc. 2nd Int. Conf. Inven. Syst. Control. ICISC 2018, no. Icisc, pp. 478-483, 2018. https://doi.org/10.1109/icisc.2018.8399118

[22] J. P. Sipani, R. H. Patel, T. Upadhyaya, and A. Desai, "Wireless sensor network for monitoring \& control of environmental factors using Arduino," Int. J. Interact. Mob. Technol., vol. 12, no. 2, pp. 15-26, 2018. https://doi.org/10.3991/ijim.v12i2.7415

\section{Authors}

Maria Beata Inka Astutiningtyas is a Master of Informatics Engineering Student of Universitas Atma Jaya Yogyakarta in Yogyakarta, Indonesia.

Monika Margi Nugraheni is a Master of Informatics Engineering Student of Universitas Atma Jaya Yogyakarta in Yogyakarta, Indonesia.

Suyoto is a Professor in the Department of Informatics Engineering at Universitas Atma Jaya Yogyakarta in Yogyakarta, Indonesia. He has more than nineteen years of teaching experience and received his Ph.D. in 2000 from the National University of Malaysia, Malaysia. His research interests are multimedia, computer graphics, visualization, mobile application, and artificial intelligence.

Article submitted 2019-12-17. Resubmitted 2020-02-15. Final acceptance 2020-02-20. Final version published as submitted by the authors. 